una amplia serie de textos que suponen sin duda significativos aportes a los estudios LGTB sobre la España franquista, de la transición y de la actualidad.

LUCIANA MOREIRA SiLVA

D.O.I.:

Centro de Estudos Sociais da

Universidade de Coimbra

\title{
Desenfocadas. Cineastas españolas y discursos de género
}

\author{
Barbara Zecchi
}

Barcelona: Icaria, 2014

La autoría fílmica ha sido raramente considerada como un objeto de estudio legítimo dentro de la teoría feminista de cine. Los beneficios de plantear la cuestión de la autoría femenina en relación con la contribución de mujeres al cine parecen menos evidentes que en el caso de la autoría literaria, lo que se traduce en la sorprendente escasez de trabajos teóricos y críticos sobre directoras de cine. Tanto la glorificación del auteur por los críticos de Cahiers du cinéma como su presunta muerte, a finales de los años sesenta, han obstaculizado la conceptualización de las cineastas como autoras fílmicas. Con la emergencia del posestructuralismo, varias críticas confesaron sus temores ante la resurrección de conceptos y prácticas esencialistas que, según ellas, deberían permanecer muertas o enterradas.

Asumiendo estos riesgos, Barbara Zecchi se propone analizar -y contextualizar - más de un centenar de películas españolas dirigidas por mujeres, corpus al cual la teórica denomina "ginocine". Desenfocadas se centra en las biografías y obras de cuatro generaciones de directoras: las "precursoras" en los orígenes de la historia de cine, las "pioneras" que trabajaron durante la guerra y el franquismo, las "progenitoras" de la Transición, y sus "herederas", las cineastas actuales. El sugerente título del volumen - “un regalo de Inés París", como señala Zecchi- alude tanto a la crisis posmoderna del auteur (implícitamente un hombre blanco, burgués y heterosexual), como a la exclusión de las mujeres por la historia y la cultura patriarcales, que no solo han borrado su presencia en el campo de la realización, sino que también han "desenfocado" las experiencias femeninas creando imágenes estereotipadas de la mujer en la pantalla. El libro de Zecchi, tal como nos lo explica su autora en la introducción, pretende devolver a las mujeres el enfoque, rescatándolas "del olvido (en el caso de la primera y de la segunda generación) o de la sombra (en el caso de las generaciones más jóvenes) en el mundo falocéntrico de la industria cinematográfica”. 
En el primer capítulo ("Cinta cero"), Zecchi documenta una presencia femenina en los comienzos del séptimo arte, demostrando que en la historia de cine español - tal y como ocurrió en muchas otras cinematografías en el mundo- se produjo el silenciamiento de una generación de mujeres cuando el cine pasó de la artesanía a la industria. Mediante numerosas entrevistas, artículos de prensa y estudios académicos, Zecchi denuncia la amnesia a propósito de la participación de la mujer en los inicios de cine, rescatando de este silencio a Carmen Pisano, Anaïs Napoleon, Beatriz Azpiazu, Elena Jordi y Helena Cortesina - cuya obra está perdida hasta la fecha - y cuestionando de esta manera la recurrente suposición de que la presencia de las mujeres en el área de la realización es relativamente reciente.

El segundo capítulo ("Cinta uno") se propone abordar las cineastas que trabajaron durante la llegada del cine sonoro, hasta ahora muy poco estudiadas: Rosario Pi Brujas, Margarita Alexandre y Ana Mariscal. Remarcando la particularidad del contexto español, Zecchi traza una serie de cambios económicos, políticos y sociales desde la Segunda República hasta la dictadura, para abordar sus implicaciones en la situación femenina dentro del ámbito de cine, tanto en lo que se refiere a la representación cinematográfica de la mujer, como a su presencia detrás de la cámara. Asimismo, Zecchi analiza cómo las cineastas estudiadas deconstruyen los patrones hegemónicos de la visión, por ejemplo mediante una inversión de la subjetividad de la mirada o mediante mecanismos de autorreferencialidad.

La "Cinta dos" se centra en las tres únicas directoras que debutan en la Transición -Cecilia Bartolomé, Josefina Molina y Pilar Miró-mostrando cómo se vieron enfrentadas a la discriminación de la industria cinematográfica española, un contexto todavía completamente dominado por el hombre. El detallado y emocionante estudio de las carreras de estas realizadoras es precedido por un análisis del cambio de paradigma en la representación de las mujeres en la filmografía española - desde los modelos de pureza característicos de la dictadura hacia las imágenes de la mujer como objeto sexual del "destape" del cine posfranquista. La teórica demuestra que la supuesta liberación durante la "apertura ideológica" de la Transición coincide con la cosificación del cuerpo femenino, la trivialización de la violencia sexual y la glorificación de los roles de género basados en la sumisión de las mujeres. Es en este contexto donde se realizan las importantes y poderosas contribuciones de las cineastas mencionadas, abordadas aquí a partir del concepto de contra-cine, es decir "un cine que contribuye al establecimiento de la mujer como sujeto feminista".

Finalmente, en la "Cinta tres", Zecchi hace un recorrido por la obra de las cineastas de las nuevas generaciones, delineando un camino desde la negación de las marcas genéricas en sus obras hacia una concienciación del género y una clara actitud política, puesta de relieve por la creación de la asociación CIMA en 2006. En este capítulo Zecchi recurre a datos empíricos para evidenciar la persistente 
discriminación de estas cineastas en la industria cinematográfica española y, por otro lado, proyecta la evolución del corpus fílmico de algunas de las cineastas más consolidadas, entre ellas Isabel Coixet, Icíar Bollaín e Inés París. La teórica se fija particularmente en los cambios temáticos (desde un cine "ginocéntrico", que aborda las cuestiones relacionadas principalmente a las experiencias femeninas, a un cine coral que corresponde a una multiplicidad de sujetos, voces y perspectivas), y formales (desde la deconstrucción del voyeurismo a la construcción de propuestas alternativas).

El libro de Zecchi es una aportación muy valiosa tanto al estudio de la presencia de las mujeres en la historiografía del cine español, como a la investigación en materia audiovisual sobre género en España, en la cual todavía predominan los enfoques sociológicos o bien las aproximaciones orientadas a la recepción a partir de metodologías de análisis de datos cuantitativos. El valor de Desenfocadas reside en una combinación de teoría feminista de cine - tanto de los trabajos ya canonizados de Laura Mulvey, Claire Johnston, Kaja Silverman o Teresa de Lauretis, como de contribuciones más recientes, por ejemplo la teoría de la visualidad háptica de Laura Marks - con un detallado y agudo análisis del contexto, basado en la inclusión de materiales parafílmicos. La multiplicidad de fuentes populares y académicas permite localizar diferentes relatos que construyen las imágenes públicas y las figuras autoriales de las cineastas españolas, que median y a la vez son mediadas a través de sus películas y de sus articulaciones públicas. El gesto de situarlas firmemente en los contextos sociales, nacionales e industriales - mediante un análisis no solo de las películas o los "hechos" de la vida de las directoras, sino también de una gran variedad de otros textos como entrevistas, críticas de cine y estudios académicos- permite entender, entre otras cuestiones, el sentimiento de orfandad ante la ausencia de una genealogía femenina, las declaraciones aparentemente antifeministas por parte de muchas cineastas, o sus intentos de negar la especificidad sexual de su obra. En lugar de juzgar o condenar estas actitudes, Zecchi las conceptualiza como diferentes posiciones estratégicas o performativas (en el sentido que Judith Butler le da al término) - una resistencia, un arma de defensa o una simple forma de supervivencia en una industria dominada por el hombre y en un contexto social en el cual un discurso hegemónico menosprecia al feminismo. Sin dejar de prestar atención a las estructuras formales o al estilo de las películas, el libro de Zecchi amplía nuestra noción sobre lo que constituye un "texto primario" en los estudios de cine, dando cuenta de una compleja red de intersecciones y divisiones - según los parámetros de Teresa de Lauretis- entre la Mujer (un constructo ideal, un producto de los discursos hegemónicos) y las mujeres (los sujetos con una especificad histórica).

Pero, ante todo, la perspicaz y minuciosa mirada crítica de Zecchi permite recuperar del olvido histórico la presencia autorial femenina y visibilizar la creación de las mujeres en el cine español, enfocando lo imperceptible y lo 
marginado en las historiografías oficiales. Desenfocadas es un proyecto revisionista de gran alcance, un libro fuente y a la vez un comentario teórico sobre el cine de mujeres, que cubre la cinematografía española desde los comienzos del cine hasta nuestros días. Un trabajo imprescindible para cualquier persona interesada en el cine español.

D.O.I.:

KATARZYNA PASZKIEWICZ

Universitat de Barcelona

\section{La condición obrera}

Simone Weil

Madrid, Trotta, 2014 (Trad. Teresa Escarpín Carasol y José Luis Escarpín

Carasol)

No es fácil presentar en pocas líneas los textos de una autora que aspiraba, como dijo a sus padres en una carta muy poco antes de morir, a "escribir cosas eternas para estar segura de que serían de actualidad". Parece que consiguió satisfacer su aspiración y lo confirma la continuidad de la edición, reedición y traducción de su obra, que despierta un sostenido y creciente interés, convirtiéndose en foco de lectura, estudio, investigación y, quizá sobre todo, de impulso eficaz del pensamiento. Tal vez la raíz de la sorprendente y enriquecedora actualidad de su aportación se encuentre en el modo en el que supo situarse en el centro de los acontecimientos para ver, sin mentirse, lo que hay y lo que falta, y en cómo supo decirlo, con una veracidad y autenticidad que continua siendo una desafiante invitación a contar con ella. Su vocación de comprender, transmitir e intervenir corresponde así a su forma de entender la filosofía como modo de vida, algo en "acto y práctica", que se concreta en una orientación de la mirada que no retrocede ante problemas y dificultades, que exige estar "en el corazón de la realidad" y es también "trabajo" con las palabras.

Pensadora política y mística, Simone Weil es autora de una obra inclasificable e imprescindible, en la que se teje su breve y muy densa biografía, como protagonista y testigo de los más dramáticos acontecimientos de la primera mitad del siglo XX, con la tarea intelectual de quien fue capaz de cultivar la atención, movida por el deseo de elaborar un diagnóstico de nuestra civilización y un proyecto de futuro. En su trayecto, personal y teórico, los escritos recogidos en La condición obrera representan un lugar literalmente central.

A finales de 1934 Simone Weil acaba la redacción de las Reflexiones sobre las causas de la libertad y la opresión social, una obra que quedará inédita aunque siempre la valorará especialmente y en la que recoge su experiencia política y su 